\title{
Pós-graduação na Amazônia: o desafio de formar (em) redes
}

\section{Graduate study in the Amazon: the challenge of forming (by) network}

\section{Posgrado en la Amazonia: el desafío de formar (en) redes}

Ronaldo de Oliveira Rodrigues, doutorando em Ciências Sociais (Antropologia) e professor da Universidade Federal do Pará. Endereço: Rua Magalhães Barata, 518. CEP: 68800-000 - Breves, PA. Telefone:(91) 9172-8115. E-mail: ronaldsa84@yahoo.com.br.

\section{Resumo}

Este artigo tem como objetivo apresentar um breve panorama da pós-graduação na Amazônia em uma perspectiva quantitativa, possibilitando comparações com as demais regiões do Brasil, bem como esboçar algumas considerações sobre os desafios e as possibilidades da formação de redes de pesquisa em uma região de características geográficas e naturais muito peculiares. Para tanto, foram utilizados dados e indicadores nacionais da pós-graduação no Brasil, além de pesquisa sobre os meios de comunicação na Amazônia, destacando-se a Internet. Conclui-se que, apesar do considerável avanço na última década, ainda se tem uma realidade inexpressiva quando comparada à do eixo Sudeste-Sul e se acrescenta que, para o alcance de expressividade, um dos caminhos é um trabalho sistemático a partir da formação de redes.

Palavras-chave: Região Amazônica. Redes Colaborativas. Internet. Universidade.

\section{Abstract}

This article aims to present a brief overview of graduate study in the Amazon in a quantitative perspective, enabling parallels with 
other regions of Brazil. It presents considerations about the challenges and possibilities of the formation of research networks in a region that features peculiar geographical and natural characteristics. National data and indicators of graduate education in Brazil were used, in addition to research on the media in the Amazon, especially the Internet. We conclude that, despite considerable progress in the last decade, the existing reality is insignificant when compared to the South-Southeast. We argue that a path for achieving greater regional expressivity is through the systematic formation of networks.

Keywords: Amazon. Collaborative Networks. Internet. University.

\section{Resumen}

Este artículo tiene como objetivo presentar una breve descripción de los estudios de posgrado en la Amazonia desde una perspectiva cuantitativa, lo que permite hacer comparaciones con las demás regiones de Brasil, así como esbozar algunas consideraciones sobre los retos y las posibilidades de la formación de redes de investigación en una región de características geográficas y naturales muy peculiares. Para ello, se utilizaron datos e indicadores nacionales de los cursos de posgrado en Brasil, además de la investigación sobre los medios de comunicación en la Amazonia, especialmente la Internet. Se concluye que, a pesar de importantes avances en la última década, todavía la realidad es insignificante si comparada con la del Sur-Sureste y que uno de los caminos para alcanzar la expresividad es llevar a cabo un estudio sistemático de la formación de redes.

Palabras clave: Región Amazónica. Redes de Colaboración. Internet. Universidad. 


\section{Introdução}

A região amazônica tem sido razão de muitos debates, que geram, simultaneamente, inquietações, otimismo, desconfiança, incertezas, novas preocupações e esperanças. Falar de Amazônia implica considerar desde questões locais até as globais, pois seu desenvolvimento, suas mazelas e, principalmente, suas riquezas naturais são de interesse não apenas do povo brasileiro, mas também de boa parte dos habitantes / empresas/universidades do mundo inteiro. É o que tem sido visto ao longo das últimas décadas.

Muitas questões ora se entrelaçam, ora extrapolam a dimensão do meio ambiente e de seus recursos naturais. Algumas vezes essa "soberania" da natureza amazônica ofusca as demais problemáticas existentes na região. Outras vezes essa mesma soberania faz pensar no quanto é preciso crescer em termos de produção de conhecimento, pois os padrões para a expansão dos conhecimentos a serem implementados na Amazônia demandam singularidade, dada sua distinção e heterogeneidade.

Destarte, somos instigados a refletir que, sem investimentos na pós-graduação na região amazônica, enfatizando Pesquisa e Desenvolvimento (P\&D) e Ciência e Tecnologia (C\&T) com vistas à criação de processos/produtos pelos próprios sujeitos amazônidas, que ainda pouco conhecem sua região, será bastante difícil promover maior desenvolvimento local.

As dificuldades enfrentadas para a consolidação de cursos de pós-graduação na Região Norte do Brasil são nítidas'. A reduzida quantidade de cursos stricto sensu representa, em parte, os obstáculos existentes. Como extensão desse aspecto está a baixa quantidade de doutores, bem como o modesto conceito Capes de boa parte dos cursos de pós-graduação nas universidades nortistas - são raros os cursos com conceito Capes acima de 4 na regiãoii-, porém devemos considerar que “a Amazônia está deixando a auréola enigmática e retórica para trás; as fronteiras do crescimento nacional estão a invadi-la, e ela deverá tornar-se o espaço mais agônico do nosso crescimento e do intercâmbio com as demais nações" (FIALDINI JÚNIOR, 2008, p. 7). 
Sem dúvida, a participação da universidade é fundamental para tal ampliação. Nessa perspectiva, com o intuito de melhor conhecer o cenário da pós-graduação na região amazônica diante das outras regiões brasileiras e ainda de ponderar as questões vistas como pertinentes e procedentes no que se refere ao melhor desenvolvimento desse nível de formação, é apresentada, em primeiro momento, uma discussão sobre o cenário da pós-graduação, incitando a necessidade de ser pensada uma maior qualificação para professores/pesquisadores e alunos da região; em seguida, propõe-se o trabalho em redes de colaboração a partir da consolidação do uso dos meios de comunicação, em especial a Internet.

\section{O cenário da pós-graduação na Amazônia: urgência da qualificação de recursos humanos}

Qualquer nação e/ou região que não possui pessoas capazes de trabalhar com as problemáticas locais está fadada à estagnação, pois o desenvolvimento é, em uma explicação mais desprendida, resultado da aplicação do conhecimento, configurando-se, na Amazônia, "uma questão de Estado, a ser debatida pelo governo e por toda a sociedade do País" (ABC, 2008, p. 10). Não há conhecimento sem investimentos, sem preparação, sem qualificação de pessoas para que elas, além de produzi-lo e transformá-lo, possam gerenciá-lo.

Os pesquisadores doutores possuem importância estratégica na cadeia de produção de conhecimentos e captação de recursos para as instituições. Além da qualificação profissional para o exercício do trabalho docente no mais alto nível de formação, a preparação para a realização de pesquisa e desenvolvimento é basilar para a transformação das próprias instituições e, consequentemente, da sociedade. Nesse caso, está justificada a afirmação de que os profissionais doutores são importantes não só para as instituições educacionais, mas também para a sociedade como um todo.

Não se pode dissociar a formação de doutores dos investimentos em P\&D e C\&T, porém, no Brasil, as diferenças em relação à aplicação desses recursos são de extrema notoriedade e contribuem 
significativamente para esclarecer as dificuldades de formação e fixação de pesquisadores na região amazônica.

Considerando os dispêndios/investimentos em pesquisa e desenvolvimento das instituições de ensino superior no ano de 2011, tendo como base a data de 5 de novembro de 2013, conforme o Ministério da Ciência, Tecnologia e Inovação (MCTI), temos:

Quadro 1. Investimentos das instituições estaduais de ensino superior - ano 2011

\begin{tabular}{|c|c|}
\hline Região & Investimentos \\
\hline Norte & 18,8 \\
\hline Centro-Oeste & 20,4 \\
\hline Nordeste & 224,7 \\
\hline Sul & 306,9 \\
\hline Sudeste & $5.259,8$ \\
\hline
\end{tabular}

Nota: em milhões de reais correntes.

Fonte: Indicadores Nacionais de Ciências e Tecnologia/MCTI. Disponivel em <http://www.mct.gov.br/index.php/content/ view/27959.html>

Quadro 2. Investimentos das instituições federais de ensino superior - ano 2011

\begin{tabular}{|c|c|}
\hline Região & Investimentos \\
\hline Norte & 328,40 \\
\hline Centro-Oeste & 801,05 \\
\hline Nordeste & $1,439,82$ \\
\hline Sul & $1,419,35$ \\
\hline Sudeste & $3.142,31$ \\
\hline
\end{tabular}

Nota: em milhões de reais correntes

Fonte: Indicadores Nacionais de Ciências e Tecnologia/MCTI. Disponivel em <http://www.mct.gov.br/index.php/content/ view/27760.html>

Em relação às universidades estaduais da Região Norte, somente duas dispõem de investimentos: a Universidade do Estado do Amazonas (UEA), com um total de 10,3 milhões, e a Universidade do Estado do Pará (Uepa), com 8,5 milhões. Como se nota no Quadro 1, a Região Norte é a que menos recebeu recursos, o que também acontece em relação aos investimentos nas universidades federais (Quadro 2). 
Quanto às universidades federais da Região Norte, pelo menos uma em cada respectiva Unidade da Federação figura com participação para a composição total dos dispêndios/investimentos. A que possui menor participação é a Universidade Federal do Amapá (Unifap), com 13,95 milhões, e a que possui maior participação é a Universidade Federal do Pará (UFPA), com 143,87 milhões (2011).

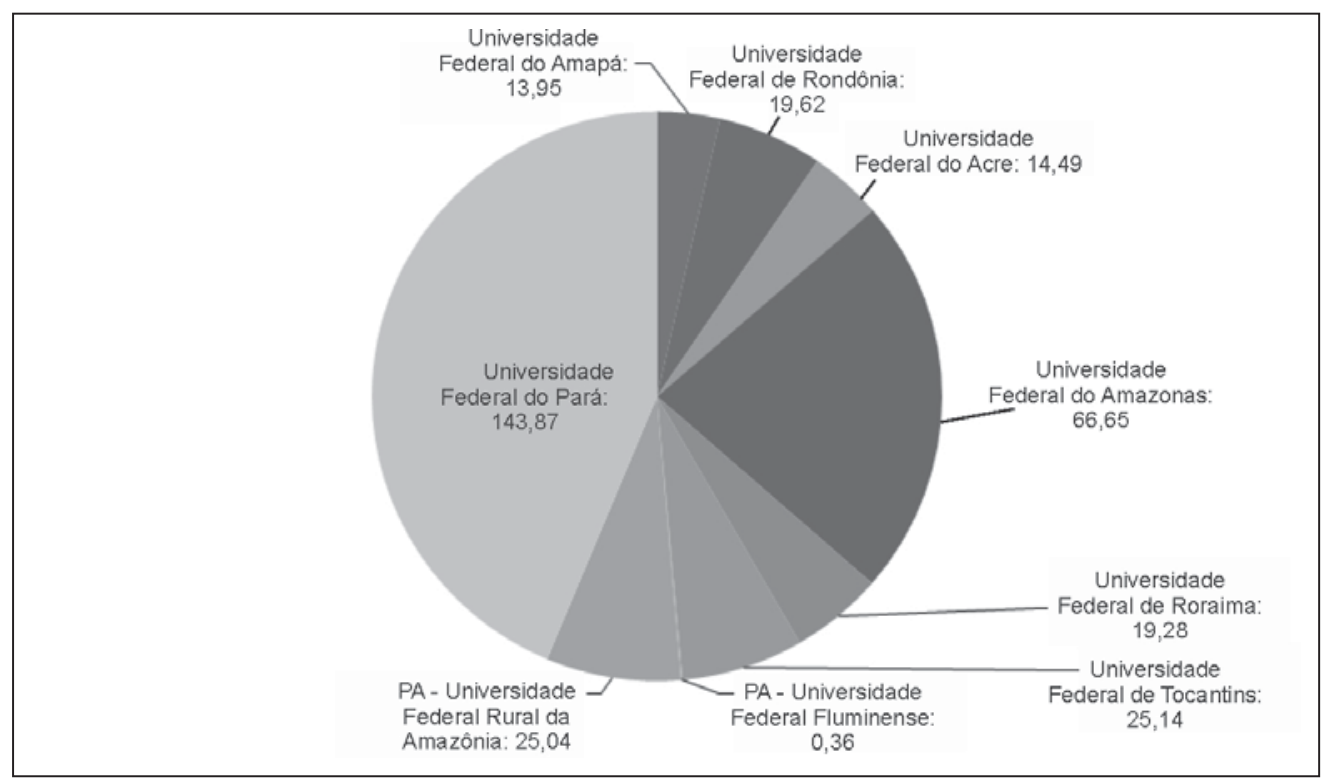

Nota: Valores em milhões.

Fonte: Ministério da Ciência, Tecnologia e Inovação.

${ }^{1}$ A Unidade Avançada José Veríssimo - UAJV, criada pela Resolução 24/72 do Conselho Universitário, está localizada no município de Oriximiná (PA) e vinculada à Pró-Reitoria de Extensão da Universidade Federal Fluminense (Proex-UFF). (Disponivel em http://www. proex.uff.br/oriximina/).

\section{Gráfico 1. Dispêndios/Investimentos das universidades federais na Região Norte (2011)}

Conforme os dados apresentados, o único estado que possui investimentos em mais de uma universidade é o Pará (UFPA, Ufra e UFF). De acordo com os indicadores do Ministério da Ciência, Tecnologia e Inovação (MCTI), a Universidade Federal Fluminense (UFF) aparece com um dispêndio de 0,25 milhão no estado do Pará em razão da presença da unidade avançada José Veríssimo no município de Oriximiná.

Não é devaneio dizer que os investimentos estão bastante relacionados ao número de cursos ofertados em nível de pós-graduação. De acordo com o Jornal Beira do Rio, da Universidade Federal do Pará,

Embora o número de cursos de pós-graduação tenha dobrado na última década - atualmente, são ofertados 4.722 em todo o País, entre cursos 
de mestrado e doutorado -, o percentual ainda é pequeno nos Estados da Região Norte, a qual possui 203 cursos de pós-graduação stricto sensu, o que corresponde a $4,26 \%$ dos cursos no País. Considerados apenas os de doutorado, esse percentual cai para 3,16\%. O Sudeste concentra o maior número de cursos, com 2.396; em seguida, está a Região Sul, com 956; o Nordeste detém 830 e o Centro-Oeste, 337 cursos (JORNAL BEIRA DO RIO, 2011, p. 3).

A oferta reduzida de cursos de pós-graduação na Região Norteii implica diretamente o baixo percentual de doutores formados e/ou presentes na região amazônica. E, em razão das problemáticas da localidade, como, por exemplo, infraestrutura e escassez de cursos na região, não há motivos atraentes para que outros pesquisadores doutores possam desenvolver suas atividades nesse lócus. Para Lafon² “É difícil uma universidade na Amazônia competir com centros de pesquisas de outras regiões. As condições de trabalho nos outros centros acabam sendo mais favoráveis, por isso é preciso ter políticas adicionais que tornem a vinda e a permanência dos pesquisadores mais atraentes".

Os que decidem imigrar e construir carreira na Amazônia acabam assumindo expoentes fardos como consequência de sua escolha. Outro problema que pode existir é a fuga de cérebros em potencial da Região Norte para outras áreas do País e até mesmo para fora dele.

É válido destacar, então, o papel da universidade na região amazônica diante dessa questão. Embora a universidade, por um lado, possibilite a qualificação de seus profissionais³ ${ }^{3}$ por outro, apresenta óbices que parecem fugir completamente do planejamento da instituição, configurando nítido paradoxo. Exemplo foi a situação vivenciada no campus universitário do Marajó-Breves (UFPA), que existe há mais de 20 anos e ainda não possui oferta regular de cursos de pós-graduação nem mesmo em nível lato sensu.

No primeiro semestre de 2014, de um corpo docente de 46 professores distribuídos em cinco faculdades, apenas quatro eram doutores, 32 mestres e nove especialistas. Em três faculdades, até meados de 2013, não havia professor com o título de doutor. No caso da Faculdade de Educação e Ciências Humanas, de um corpo de 12
2 Entrevista ao Jornal Beira do Rio (UFPA), nov. 2011 p. 13.

${ }^{3}$ Os programas de apoio à qualificação de servidores docentes e técnicos administrativos constituem exemplo dessa afirmação. 
docentes, apenas um possuía doutorado; uma professora estava com liberação total para estudar; e havia outro docente que cursou um ano de seu doutorado conciliando as atividades do curso com as atividades docentes na graduação, tendo liberação para estudo apenas no início de 2013.

O local geograficamente mais próximo do campus do MarajóBreves que oferta cursos de doutorado é Belém, capital do Pará. O tempo de viagem de um local para o outro, em média, é de, pelo menos, 12 horas. É possível imaginar o desgaste que isso gera ao professor que se submete a tal situação, tendo que, em alguns dias, se dedicar completamente às atividades de doutoramento na condição de discente e, em outros, dar tudo de si para não deixar a desejar em sala de aula como docente. No meio de tudo isso, boas horas de viagem tornam essa rotina um pouco mais cansativa.

No final de 2012, três professores da referida faculdade conseguiram aprovação para iniciar seu doutoramento no ano de 2013. No primeiro momento, não conseguiram a liberação para estudar em razão do déficit gerado na faculdade com sua saída e da necessidade de discussão de critérios para a concessão de afastamento para estudo. Em um segundo momento, os professores conseguiram a liberação na unidade de trabalho, porém condicionada à contratação de professor substituto. Contudo, no mesmo período, devido ao modelo de política adotado pelo Governo Federal, a universidade considerou inviável a contratação de professor substitutoiv. Os desdobramentos da situação apontaram para a liberação em tempo integral de dois professores e a desistência do processo por parte de um deles - em sua dinâmica de trabalho, este concilia as atividades de trabalho com as de estudo.

Se essa condição de impasse persistir, é muito provável que ainda tenhamos, no mínimo, mais duas décadas sem que haja cursos de pós-graduação naquele campus, levando-se em conta o fato de que, para saírem para estudar - por exemplo, dois professores por faculdade a cada quadriênio -, os docentes devem esperar os colegas concluírem seus cursos e retornarem, o que parece não ser a política indicada para o crescimento da universidade. O ideal é a oferta de cursos na própria instituição. 
Há pontos contraditórios na política governamental que orienta a dinâmica de formação universitária. A Lei n ${ }^{\circ}$ 12.772, de 28 de dezembro de 2012, que dispõe sobre a estruturação do Plano de Carreiras e Cargos de Magistério Federal, em seu Capítulo IX, "Dos Afastamentos", art. 30, dispõe que "o ocupante de cargos do Plano de Carreiras e Cargos do Magistério Federal, sem prejuízo dos afastamentos previstos na Lei ${ }^{\circ}$ 8.112, de 1990, poderá afastar-se de suas funções, assegurados todos os direitos e vantagens a que fizer jus". Conforme o inciso I do referido artigo, o interessado poderá "participar de programa de pós-graduação stricto sensu, independentemente do tempo ocupado no cargo ou na instituição". Destaca ainda o $\S 2^{\circ}$ do art. 30, que "aos servidores de que trata o caput poderá ser concedido o afastamento para realização de programas de mestrado ou doutorado, independentemente do tempo de ocupação do cargo".

Essa nova lei, caso respeitada e posta em prática, tende a beneficiar em muito a política de expansão das universidades do Norte do País no que se refere aos cursos stricto sensu, considerando que há um déficit muito grande de doutores, como mencionado anteriormente. Porém, como visto no caso citado - o do Marajó-Breves -, o exercício dessa nova legislação ainda não se dá de forma plena.

O investimento maciço na pós-graduação na região amazônica deve trazer avanços, tais quais os que começaram a serem vivenciados no eixo Sul-Sudeste há cerca de 30 anos, pois, de acordo com Marchelli (2005), até o ano de 1985, mais de 40\% dos doutores brasileiros tinham obtido seu título em instituições estrangeiras. Nos anos posteriores, houve significativa evolução no número de doutores formados em universidades brasileiras. Logo, compreende-se que a política priorizou formar doutores no País, meta que poderia ser direcionada neste momento para a Amazônia.

Com um baixo número de doutores, a qualificação do corpo docente que atua na graduação é baixa, o que incide diretamente na qualidade da formação daqueles que serão os futuros cientistas, pretensos candidatos aos cursos de pós-graduação e responsáveis pela renovação/produção de conhecimento, bem como pela ocupação de cargos de docência e pesquisa. 
É fato que a pós-graduação brasileira sinaliza para a conquista de espaço significativo no cenário mundial da produção de conhecimento. Esse espaço já é de destaque quando comparamos o Brasil aos países emergentes, mas, quando são consideradas as grandes potências, ainda precisamos avançar muito, até porque é a Região Sudeste que mais tem dado o tom da participação do Brasil quando os assuntos são produção acadêmica, pesquisa na pós-graduação, iniciação científica e outros do gênero.

Qualificar pessoas em nivel stricto sensu significa não apenas otimizar a pesquisa com recursos vitais para o desenvolvimento de uma nação, mas também reduzir expressivamente a dependência diante de pesquisadores estrangeiros ${ }^{4}$, possibilitando dar maior autonomia e expressividade à produção brasileira, bem como alavancar a possibilidade de compreensão das problemáticas locais.

A qualificação de pessoas implica também tornar as instituições mais competitivas no que se refere à captação de recursos, proporcionando, então, maiores possibilidades para a consolidação de novas pesquisas, a partir, por exemplo, das redes colaborativas, elemento vital para a iniciação científica e consolidação da pesquisa e que será discutido posteriormente neste trabalho.

[...] A existência desses recursos humanos qualificados é essencial para o aumento das vantagens competitivas de base tecnológica, porque tais vantagens dependem de nossa capacidade de absorver, transformar e produzir novos conhecimentos e inovação. Em qualquer país, a pósgraduação forma uma reduzida parcela da mão de obra qualificada, mas essa parcela específica tem papel fundamental na formação de multiplicadores de recursos humanos qualificados e, em especial, na formação de doutores, que são profissionais com capacidade para realizar pesquisa e desenvolvimento original (MELO, 2010, p. 9).

4É claro que a contribuição deles é essencial, porém não na condição de a pesquisa e produção brasileira serem completamente dependentes da produção estrangeira. 
A presença/participação/circulação de doutores nas diversas instituições que compõem a sociedade deve trazer significativos benefícios para o desenvolvimento das mais variadas atividades e setores, nos âmbitos econômico, político e/ou cultural.

O descompasso das realidades existentes, considerando a quantidade de doutores formados no Brasil, é claramente ratificado quando se tem dados que levam em conta a titulação dos concluintes em um período de tempo de 12 anos nas cinco regiões brasileiras.

Instituições localizadas na Região Sudeste titularam 67.626 doutores, o que correspondeu a 77,7\% dos 87.063 doutores titulados no Brasil no período 1996-2008. A Região Sul titulou 6 vezes menos doutores do que a Sudeste no mesmo período, enquanto que as Regiões Nordeste, CentroOeste e Norte titularam respectivamente cerca de 12, 32 e 106 vezes menos do que a região que mais titulou doutores. Essas proporções dão uma clara indicação do elevadíssimo grau de concentração regional do processo de formação de doutores existente no Brasil (CGEE, 2010, p. 32).

Para se ter uma ideia mais consolidada do grau de concentração, vale citar que, no período de 1996-2008, somente a USP titulou 23.372 doutores; já as universidades da Região Norte titularam 639 (CGGE, 2010), ou seja, mesmo juntas, as universidades localizadas na parte de cima do mapa brasileiro titularam somente $2,7 \%$ do total de doutores de uma única universidade da Região Sudeste.

Se considerarmos que a comparação é incabível porque a USP é a maior universidade brasileira em titulação de doutores, podemos buscar outro exemplo entre as cinco universidades que mais titulam no Brasil - USP, Unicamp, UFRJ, Unesp, UFRGS. A UFRGS é a que menos formou doutores no período de 1996-2008 (4.070) e, mesmo em comparação com ela, a quantidade de doutores formados nas universidades do Norte representa apenas 15,7\%. Já se somarmos o total de doutores titulados no mesmo período em toda a Região Sudeste, vamos ter um quantitativo de 67.626 e, nesse caso, o total de doutores formados no Norte alcança pouco menos de 1\%. É o que apresentamos no Gráfico 2. 


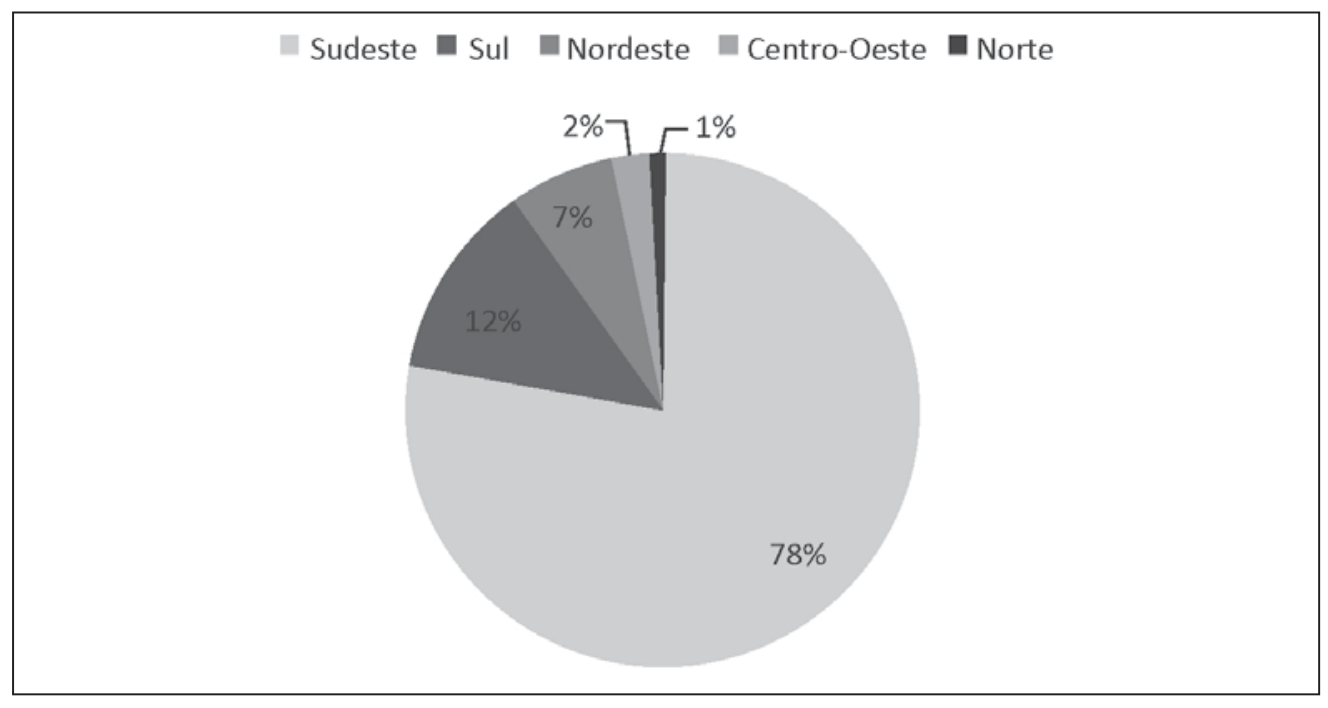

Fonte: CGEE, 2010.

\section{Gráfico 2. Doutores titulados por regiões brasileiras (1996-2008)}

Para Costa (2012), em 1989, eram seis os cursos de doutorado na Região Norte; em 1995, esse número passou a ser nove. A partir desses cursos, formaram-se, até o ano de 1995, 73 doutores na região. Por sua vez, o crescimento atual é expresso a partir da afirmação de Emmanuel Tourinho, pró-reitor de Pesquisa e Pós-Graduação na UFPA: "Para se ter uma ideia, no ano de 2001, a UFPA tinha 23 cursos de pós-graduação stricto sensu, sendo 16 cursos de mestrado e sete, de doutorado. Em 2011, uma década depois, passamos para 78 cursos, sendo 52 de mestrado e 26 de doutorado." (JORNAL BEIRA DO RIO, 2012, p. 3).

\footnotetext{
O aparato de pesquisa da Região Norte comparado à média e ao extremo superior das regiões brasileiras, apresenta a seguinte situação: em termos absolutos, os quadros reais de pesquisadores correspondem a 2,4\% do total do Brasil; sua equivalência qualificada por seu turno, representa bem menos: 2,1\%. É que o índice de qualificação representa apenas 88\% da média brasileira, dada a menor representatividade dos doutores nos quadros de pesquisadores, uma vez que na região encontram-se tão somente $1,6 \%$ do total de doutores pesquisadores no País [...] A Região Sudeste apresenta proporções inversas: $67,4 \%$ dos pesquisadores nacionais e $72 \%$ dos doutores entre eles, com rebatimento correspondente no Índice de Qualificação (COSTA, 2012, p. 44).
}

Segundo Costa (2012), o índice de qualificação é um indicador de excelência e baseia-se na seguinte expressão matemática: [ (nº 
de graduados $\times 1)+\left(n^{\circ}\right.$ de mestres $\left.\times 3\right)+\left(n^{\circ}\right.$ de doutores $\left.\left.\times 5\right)\right] /\left(n^{\circ}\right.$ de graduados $+n^{\circ}$ de mestres $+n^{\circ}$ de doutores). Um dos principais objetivos da utilização desse indicador é o volume de pesquisas desenvolvidas relacionadas à qualidade do ensino, bem como a verificação do nível de titulação dos responsáveis pela produção.

Sabe-se que educação de qualidade é condição para redução da pobreza, embora não seja o único fator responsável para que o desenvolvimento econômico esteja garantido. Contudo, dificilmente haverá educação de base consolidada se os niveis mais elevados não oportunizarem, de fato, qualidade em seu processo.

Shott (1993 apud COSTA, 2012, p. 57) considera que:

A ênfase no ensino (e a ausência de pesquisa) na grande maioria das instituições brasileiras, associada ao pouco treino dos estudantes e professores em pesquisa científica; as descontinuidades no fornecimento de recursos financeiros para a pesquisa associadas à falta de enraizamento e amplitude da ideia da ciência como valor em si mesmo e como meio para o desenvolvimento nacional configuram [...] as razões da baixa performance do empreendimento científico no Brasil.

Embora no eixo Sul-Sudeste essa realidade de baixa performance no ensino e na pesquisa já esteja em muito alterada, na Região Norte a realidade comentada é plenamente cabível. Por exemplo, antes mesmo de chegar à pós-graduação, o acadêmico deve ter o mínimo de condições de perceber como se desenvolvem as atividades em cursos stricto sensu. Esse é um privilégio do qual muitos acadêmicos amazônidas não desfrutam.

Participar de grupos de pesquisa e de projetos de extensão, desenvolver atividades de iniciação científica, elaborar e publicar artigos científicos, em grande maioria, são especificidades de cursos ofertados nas capitais, onde a infraestrutura é melhor e o corpo docente mais bem qualificado. Nesse sentido, a dificuldade dos alunos do interior está não somente em concluir seu curso de graduação, mas, consequentemente, também na conquista de vagas nos cursos de pós-graduação stricto sensu, além, é claro, das enormes distâncias geográficas em relação à capital, como no caso do estado do Pará. 


\section{O desafio da constituição de redes (colaborativas) de pesquisa na Amazônia}

Gerenciar o conhecimento na sociedade atual demanda novas estruturas organizacionais visando a diferentes formas de atuação com o intuito de produzir e agregar conhecimentos àqueles já existentes. Quando falamos de conhecimento, "estamos falando de uma variedade de atividades que vão desde a geração do conhecimento puro (ciência) e aplicado (tecnologia) até a capacidade de, a partir dele, produzir riqueza (inovação)" (STEINER, 2006, p. 75).

Em um momento em que a própria sociedade se apresenta como rede - efêmera -, é fundamental que essa mobilidade seja apropriada, porque suas características se diluem para as demais instituições sociais, o que acaba replicando na universidade e, naturalmente, em suas práticas cotidianas.

No tocante à pós-graduação, uma questão estratégica a ser explorada para a sua consolidação na Amazônia são as redes colaborativas ou cooperativas de conhecimento. As redes cooperativas de pesquisa são excelentes estratégias para a produção, gestão e transmissão do conhecimento, principalmente em áreas como a região amazônica, onde o acesso e translado - considerando o aspecto geográfico - são bastante difíceis.

O conceito de redes refere-se a:

[...] arranjos de pessoas ou grupos que mantêm conexões com um ou com todos os outros integrantes. As pessoas ou os grupos são os atores (nós da rede), e os projetos de pesquisa e pós-graduação são as conexões. Um ator pode ser uma única pessoa, um grupo ou um programa de pósgraduação e pesquisa (ROCHA NETO, 2010, p. 60).

Esse conceito ganha força na nova estrutura social vivenciada, em que há novos padrões de sociabilidades demarcados pelas transformações tecnológicas que reconfiguram a relação dos indivíduos, bem como a dinâmica da própria sociedade, ou seja, o seu próprio formato de organização social: o da sociedade em rede (CASTELLS, 2008). 
É importante esclarecer que não se refere aqui somente à formação de redes entre universidades diferentes, mas também ao estabelecimento de redes entre profissionais de uma mesma universidade presente em diferentes localidades e, por isso, dispersa, uma vez que, por exemplo, no caso da Universidade Federal do Pará, há locais em que, para se ir de um campus do interior ao campus sede, a viagem pode durar de seis a 14 horas.

Os vetores das redes cooperativas apontam para a necessidade de mudança de pensamento acerca da ideia de competência estática, em que um pesquisador, dadas as distâncias geográficas, não podia expandir suas contribuições, ora porque não havia como ter um contato facilitado com pesquisadores de outras regiões, ora pela dificuldade em ter acesso à produção destes.

Trabalhar em rede significa romper com a zona de conforto de profissionais sem desejo e/ou motivação para novas investidas ligadas ao processo de inovação, palavra que conduz a caminhos muito pouco conhecidos na Amazônia. A inovação tem vários significados, mas pode ser caracterizada como busca, descoberta, experimentação, desenvolvimento e adoção de novas ideias / produtos para alavancagem da criatividade. É ter uma nova ideia e aplicá-la, causando significativa transformação no processo de produção/transformação de determinado objeto/produto.

A inovação tem sido um tema muito debatido atualmente, tanto que, desde o dia 10 de agosto de 2011, o então Ministério da Ciência e Tecnologia do Brasil passou a ser Ministério da Ciência, Tecnologia e Inovação (MCTI). A questão é que a incorporação do novo termo não trouxe elementos diferenciados às funções já exercidas pela Pasta, mas demonstra claramente que é um conceito que permeia as ações do campo da Ciência e Tecnologia e, por isso, passa a compor um tripé em consolidação no Brasil.

As novas possibilidades geradas pelo trabalho cooperativo interligado pelos avanços da informática e dos meios de comunicação massiva criam condições para significativas alterações, desde a 
consolidação dos grupos de pesquisa, passando pelo processo ensinoaprendizagem e incidindo sobre os resultados obtidos, que serão ainda mais exponencializados.

Mesmo com as limitações dos recursos ofertados pelos meios massivos na Amazônia (MALCHER; RODRIGUES, 2012), não se pode remeter a segundo plano o fenômeno de midiatização em que vive a sociedade. Sobre esse fenômeno Mattos e Villaça (2011) consideram que

Assumindo a midiatização como nova ordem comunicacional na qual as mídias são mais uma 'variável dependente', estudiosos desse fenômeno o encaram como processo que atinge não apenas determinados âmbitos das sociedades, mas que se desenvolve e engloba todas as instâncias sociais, chegando a constituir-se como nova forma de sociabilidade (p. 12).

Os esclarecimentos sobre o fenômeno de midiatização, portanto, demandam a necessidade de compreensão de que os meios formam/ tecem a dinâmica da sociedade atual e não simplesmente interferem ou atravessam, como um corpo/objeto estranho, a realidade existente.

Nesse sentido a dinâmica do cotidiano em suas rotinas, sejam as de produção, sejam as de recepção, é tecida pela mídia, com a necessidade de apropriação cada vez maior das instituições sociais, o que gera uma extensa demanda para a universidade em seus cursos de pós-graduação, por serem eles os responsáveis por proporcionar formação de mais alta qualidade na instituição.

É claro que óbices serão enfrentados para a consolidação de uma dinâmica cooperativa de pesquisa na Amazônia a partir dos meios de comunicação massiva, pois, em muitos municípios, boa parte dos serviços ainda é muito recente e/ou apresenta grande instabilidade, e os elementos de ordem natural, principalmente as densas florestas, contribuem bastante para essa realidade (RODRIGUES, 2012).

Por seu crescimento inquestionável, é importante destacar a dimensão ocupada pela Internet e suas características nesse cenário, pois é notável o aumento do acesso a essa mídia na regiãovi. Esse 
processo é acompanhado de alguns fatores, tais como: o crescimento do número de usuários, o aumento do número de rádios on-line, os conteúdos dos jornais impressos e também em formato digital e a disponibilização do conteúdo de programas de TV na Internet.

É interessante considerar que o crescimento de conteúdo e serviços na rede não pode ser entendido como sinônimo de fácil acesso ou, ainda, de serviço de qualidade considerável. Ou seja, os serviços crescem sem a qualidade almejada - baixa velocidade e capacidade da rede, falta de políticas públicas de inclusão da população, custos não tão acessíveis para a realidade da maior parte das pessoas etc.

Entre os sites mais acessados na Região Norte, as ferramentas de busca lideram com 40,67\%. Redes sociais e fóruns aparecem em seguida, com 24,96\%; e-mails, com 9,39\%; homepages, com 7,63\%; e sites, de entretenimento, com 7,16\% dos acessos. Esses dados demonstram que os interesses são variados, mas há uma convergência para a dinâmica de interação nas redes sociais (HITWISE, 2011).

Mesmo com as dificuldades enfrentadas quanto ao uso da Internet na região amazônica, afirmamos que esse recurso é fundamental para a composição de redes de pesquisa, grupos de estudo e de circulação/divulgação dos conhecimentos produzidos, pois embora "a formação de redes seja uma prática humana muito antiga, elas ganharam vida nova em nosso tempo, transformando-se em redes de informação energizadas pela Internet” (CASTELLS, 2003, p. 7).

Exemplo dessa interligação possível é a pesquisa de âmbito nacionalvii liderada pela Profa. Dra. Nilda Jacks, da Universidade Federal do Rio Grande do Sul, intitulada Jovem e consumo cultural/midiático em tempo de convergência (2011-2014). A pesquisa envolveu todos os estados brasileiros. Equipes estaduais foram formadas nas capitais, e outras foram além, conseguindo estender-se e formar grupos em cidades do interior; a comunicação se dá basicamente pela Internet, sendo que os eventos presenciais da área da comunicação (principalmente Intercom e Compós) são utilizados como espaços estratégicos para a socialização do andamento/resultado das pesquisas. 
Embora não seja uma proposta exclusivamente em nível de pós-graduação, a participação dos alunos da Região Norte, seja de graduação, seja de pós-graduação, demonstra que, com planejamento e organização, é possivel articular, compartilhar, orientar e distribuir tarefas a partir da rede.

Alves (1999) considera que em rede se tecem os saberes e as subjetividades que formam os sujeitos que nela se relacionam. Desse modo, os sujeitos que compõem a(s) rede(s) são privilegiados por participarem da construção de saberes tecidos em grupo, porém não se desprezam as experiências e os conhecimentos individuais, pois a rede se fortalece porque agrega e otimiza de maneira conjunta a participação de vários pesquisadores, e a riqueza gerada está justamente no diálogo entre diferentes repertórios.

Uma das possibilidades para alavancar a produção, pesquisa e troca de experiências em âmbito acadêmico está no uso da Internet, que, mesmo com suas limitações em termos de funcionalidade, sinaliza bons frutos a partir da comunicação por ela permitida.

Exemplo dessa questão, resguardadas as devidas proporções, são as transmissões ao vivo - via Internet - feitas pelo Programa de Pós-Graduação em Comunicação, Cultura e Amazônia (PPGCOM)5, da Universidade Federal do Pará, seja nas aulas inaugurais, seja na realização de eventos/momentos de extrema importância para a circulação das/ dos informações/conhecimentos ali gerados, permitindo, assim, que várias pessoas interessadas no assunto possam acompanhar/participar do evento, mesmo não estando presentes fisicamente.

5 Segundo Programa de Pós-Graduação do Norte do Brasil criado no ano de 2010 e coordenado pela Profa. Dra. Maria Ataide Malcher. No link <http:// www.ppgcom-ufpa.com. br/biblioteca.html>, é possivel ter acesso ao conteúdo multimídia disponibilizado pelo programa.

As potencialidades geradas por esse tipo de recurso devem atuar como marco histórico para a definição de novas diretrizes no que concerne à consolidação da pós-graduação na Amazônia, pois, direta ou indiretamente, os alunos e professores acionam recursos da Internet para a operacionalização de suas atividades.

Estar aberto ao novo é fator determinante diante da concepção de trabalho cooperativo a partir dos meios massivos, pois eles podem 
permitir uma forma diferente de investigar/adentrar a realidade de uma região de tão difícil acesso geográfico, como é a Amazônia.

O conhecimento dentro das redes ganha tessitura específica ao permitir a expansão, a interatividade - que ainda é um conceito que precisa ganhar em discussão e praticidade - e o estabelecimento de links e de outros mecanismos/recursos permitidos pelas teias virtuais. Com isso, novos saberes, novas práticas e novas inquietações levam a uma esfera nunca antes pensada.

É certo que a proposta de articulação de pesquisa em rede na pós-graduação amazônica depende de planejamento e bastante empenho por parte de seus envolvidos. Nesse sentido, destaca-se que a participação discente é elemento exponencial, sem o qual não se conseguirá avançar.

A avaliação constante do processo é uma característica fundamental para o sucesso da proposta. A partir desses elementos, será possivel ter recursos humanos em contínua formação e a expansão da rede, o que abrirá um leque de oportunidades para a formação de novas ramificações conectadas a uma rede maior.

De acordo com Kohn (1994 apud PAIVA; MACIEL, 2000), a rede atravessa o espaço, o tempo e a dinâmica da ordem estabelecida, possibilitando a integração de elementos dispersos, criando um território intersticial. No limiar dessa questão surgem os componentes centrais de uma rede: sua base material, que engloba a técnico-organizacional - inclusive infraestrutura -, e as relações (inter)pessoais dentro de sua configuração .

É importante pontuar que a participação e o envolvimento das pessoas é fundamental, assim como a necessidade de uma infraestrutura mínima. Não há como avançar no processo, mesmo com pesquisadores do mais alto nível e com excelentes intenções, se não há infraestrutura para trabalhar - questão válida não somente para o trabalho em rede. Da mesma maneira, não será vantagem contar com a melhor infraestrutura se as pessoas não estão dispostas/aptas a colaborar e trocar conhecimentos para o fortalecimento da rede. 
A consolidação da rede para a sedimentação e/ ou fortalecimento da pós-graduação na Amazônia exige que não se use a Internet como em muito tem sido utilizada por outros setores da sociedade. Ou seja, devese romper com a ideia de plenitude informativa na contemporaneidade, em que a sensação de estar informado é suficiente.

Construir teias virtuais, portanto, requer imersão, aprofundamento, pesquisa e participação. Participar é construir, e a ideia de simplesmente estar informado não basta, pois a gramática da pós-graduação em rede colaborativa demanda experimentação, mas, principalmente, interação.

Sabe-se que, desde o final dos anos 1960, a pós-graduação brasileira vem sendo avaliada a partir de um conjunto rigoroso de critérios que compõem uma política de cunho estritamente qualitativo - qualidade ainda mantida e expandida atualmente. A inquietação que surge é: não poderia ser a consolidação da pós-graduação na Amazônia mais acelerada, considerando o potencial da formação de redes colaborativas a partir do uso dos meios massivos, em especial a Internet?

As redes devem constituir um espaço democrático, em que o convívio possibilite trocas e experimentações que superem o cristalizado saber estático e tradicional com o qual gerações tiveram que se adaptar e reproduzir. Um saber que, embora possa ser criticado, em certa medida tem características - como disciplina e empenho - fundamentais para o sucesso da produção de conhecimento nos dias atuais e que poderiam ser apropriadas para um novo modelo de formação (em redes).

Deve-se atentar ainda para o fato de que as redes supõem uma mobilidade não somente material, mas também simbólica, oportunizando, por exemplo, que as características culturais de cada grupo de pesquisa possam ser apropriadas por membros de diferentes localidades.

Um dos maiores benefícios da composição de redes é a comunicação e a organização de forma horizontal, em que não há apenas um responsável para socializar o saber, mas, sim, várias pessoas que se comunicam e trocam ideias em um espaço democrático de conhecimento. 
Esse processo colaborativo a partir de rede virtual pode trazer vários benefícios de ordem prática, tais como superar uma possível desintegração causada em razão das distâncias geográficas e mesclar em um grupo de pesquisadores tanto pessoas mais experientes quanto iniciantes, reduzindo as possibilidades de haver qualquer receio ou preconceito, seja por parte dos mais jovens, seja por parte dos mais experientes.

Castells (2008) considera irreversível o fenômeno da informatização, bem como a expansão desse fenômeno pelas instituições sociais e por todo o mundo, o que implica pensar na questão da midiatização. Portanto, é fundamental a criação de condições para a ocorrência desse processo nas universidades da região amazônica, principalmente se a projeção for a de se ter tanta riqueza em termos de produção de conhecimento quanto tem sido celeiro para pesquisadores de todo o mundo.

Nessa perspectiva, um dos caminhos - quem sabe o mais indicado? - para a consolidação do início do processo que aqui podemos caracterizar como “inteligência coletiva” (LEVY, 1999) na Amazônia deve ser fomentado a partir dos cursos de pós-graduação, pois algumas exigências desse nível de formação podem ser essenciais para manter o foco de uma rede que preze pelo conhecimento.

Destaca-se, portanto, a interconexão que se caracteriza por propor uma troca de relações e saberes. "A conexão é um bem em si” (Ibidem, p. 127). Podemos dizer que hoje estar conectado ao saber demanda desconectar-se da superficialidade da própria rede para mergulhar no mundo da pesquisa de maneira comprometida e planejada, fazendo as relações necessárias entre os links territoriais e os virtuais.

Dada a mudança das características de navegação a que o amazônida habitualmente estava acostumado, a imersão em novas teias deve trazer significados igualmente novos. Um deles é o de que a sociedade em si é uma rede, não para propor elementos estáticos, mas dinâmicos, como rege a gramática da própria pós-graduação. 


\section{Considerações finais}

A Amazônia, historicamente visualizada por suas riquezas naturais e classicamente submetida a papel secundário, apesar de sua potencialidade de produção de conhecimento, está diante da iminente possibilidade de começar a alterar essa imagem. A fronteira que demarca tal questão está na realização de pesquisa e produção de conhecimento.

Nesse sentido, o papel da universidadeé vital e, consequentemente, a pós-graduação assume condição sine qua non para dirimir a dinâmica de realização de pesquisa e outras atividades peculiares próprias de sua gramática, que devem atuar na base de um movimento em que a produção de conhecimento na própria região seja o foco.

A comparação com as demais regiões do Brasil em termos quantitativos foi importante para situar como vem se dando o movimento da pós-graduação na Amazônia. Vimos que não há estaticidade em relação aos avanços quantitativos, pelo contrário, a última década foi diferencial para o crescimento, embora a passos lentos, de cursos de pós-graduação na região. Esse crescimento, porém, ainda é bastante inexpressivo diante da realidade nacional, e há extrema necessidade de os cursos existentes serem ainda mais qualificados, na busca de um nível de excelência, principalmente porque são escassos os cursos com conceito Capes acima de 4.

Como alternativa para a superação dessa problemática, esboçamos algumas considerações sobre os desafios e as possibilidades da formação de redes de pesquisa em uma região de características geográficas e naturais distintas. Acredita-se que, apesar das restrições de funcionamento, os meios de comunicação, em especial a Internet, podem ser elementos diferenciais para dinamizar, potencializar e contribuir para a formação/consolidação de redes colaborativas, que apresentam características viáveis para acelerar - e com qualidade - o crescimento e fortalecimento da pós-graduação na Amazônia, instigando uma cultura de pesquisa.

Por fim, é importante considerar que áreas como Tecnologia da Informação e Comunicação, Biodiversidade e Biotecnologia são 
estratégicas e urgentes no que diz respeito à formação de doutores na Amazônia, pois ações/investimentos nessas áreas a partir da qualificação de recursos humanos poderão se desdobrar em outras importantes ações nos mais diversos setores da sociedade.

\section{Notas explicativas}

'Em março de 2011, durante a realização do Fórum Regional de PróReitores de Pesquisa e Pós-Graduação das IES Brasileiras, em Boa Vista, Roraima, essa problemática foi o foco das discussões. Como resultado, elaborou-se a Carta de Boa Vista, "na qual constam informações sobre as diferenças regionais em relação ao desenvolvimento da ciência e da pós-graduação e propostas para superá-las, como a qualificação dos docentes das instituições de ensino superior que estão na Amazônia (JORNAL BEIRA RIO, 2011, p. 3).

ii Para citar um exemplo, temos que, de acordo com o Relatório Anual 2012 da Pró-Reitoria de Pesquisa e Pós-Graduação (Propesp) da Universidade Federal do Pará (UFPA), a universidade tinha 26 cursos de doutorado, 47 cursos de mestrado acadêmico e nove cursos de mestrado profissional, distribuídos a partir de 61 Programas de Pós-Graduação. Desse total, quatro programas tinham cursos com conceito 5 (como, por exemplo, os casos dos cursos de mestrado e doutorado em Direito, Genética e Biologia Molecular) e apenas um (Geologia e Geoquímica) apresentava conceito 6 (UFPA, 2013).

iii Mesmo dadas as dificuldades, deve-se reconhecer que o crescimento da pós-graduação da UFPA, ao longo da última década, foi considerável, passando de 30 mestrados e doutorados, em 2003, para 86, em 2013. No mesmo período, a instituição alcançou maior reconhecimento científico dentro e fora do País, com elevado grau de internacionalização de sua produção. Apenas entre a Avaliação Trienal de 2010 e a Avaliação Trienal de 2013, um intervalo de três anos, o número de cursos de pós-graduação da UFPA cresceu $29 \%$ (19 cursos a mais). No doutorado, esse crescimento foi de $42 \%$, passando de 19 para 27 cursos, o que novamente atesta que a expansão está acontecendo com qualidade e reconhecimento externo dos programas (TOURINHO, 2014, p. 4). 
iv No dia 24 de abril de 2013, a Pró-Reitoria de Planejamento e Desenvolvimento Institucional/UFPA enviou o memorando circular $n^{\circ}$ 02/2013 endereçado às unidades e subunidades acadêmicas e regionais, tendo como assunto a contratação de professores substitutos. 0 item de abertura do memorando trazia a afirmação de que "atualmente a universidade não possui espaço no banco de professores equivalentes para a contratação de substitutos, em razão da redução do banco de professores da UFPA realizada pela Portaria Interministerial $n^{\circ} 24$, de 5 de fevereiro de 2013”.

v Essa parece ser a proposta apresentada pelo campus do MarajóBreves, uma vez que, em 2014, devem ser ofertadas uma turma de Mestrado em Gestão Pública - a partir de convênio com a Prefeitura Municipal de Breves - pelo Programa de Pós-Graduação em Gestão Pública/Belém/UFPA e uma turma de Doutorado em Antropologia, pelo Programa de Pós-Graduação em Antropologia/Belém/UFPA. O grande problema dessa oferta é que profissionais de diversas áreas (Letras, Matemática, Pedagogia, Serviço Social e Ciências Naturais - que são os cursos com oferta regular no campus) devem submeter-se a um curso que talvez não seja de seu desejo, e muitos deverão fazêlo por ser a oportunidade que surgiu, podendo comprometer vários aspectos de sua formação e a de seus futuros alunos. É certo que, por outro lado, poderemos defender a proposta de interdisciplinaridade. Independentemente dos resultados, já temos uma ação significativa com o intuito de equacionar a problemática da formação de recursos humanos.

vi Segundo pesquisa do Hitwise, um serviço da Serasa Experian que monitora o comportamento anônimo e agregado na internet de mais de 500 mil pessoas espalhadas geograficamente de maneira que representem a distribuição da população on-line brasileira, em mais de 270 mil websites em todo o País, a Região Norte é a que mais cresce em acessos à Internet (18/04/2011). Disponivel em: <http:/ / www.digitalmarkketing.com e http://g1.globo.com/tecnologia/ noticia/2011/04/presenca-da-regiao-norte-na-internet-brasileiracresce-19-diz-pesquisa. html>. Acesso em: 20 abr. 2011. 
vii Projeto financiado pelo CNPq, desdobrado em outras pesquisas estaduais apoiadas pelo mesmo órgão. Na Região Norte, o estado do Pará foi contemplado com fomento a partir do projeto Jovens em tempo de convergência: pesquisa exploratória de recepção dos usos e apropriações de recursos multi-midiáticos no Pará-Amazônia-Brasil, coordenado pela Profa. Dra. Maria Ataide Malcher. Para saber mais sobre o projeto nacional, acessar <http://redebrasilconectado.wordpress. com/projeto>.

Recebido em: 30/04/2013

Aprovado em: 17/03/2014

\section{Referências bibliográficas}

ABC - Academia Brasileira de Ciências. Amazônia: desafio brasileiro do século XXI. São Paulo: Fundação Conrado Wessel, 2008.

ALVES, N. Tecer Conhecimento em Rede. Rio de Janeiro, 1999. 11p. [mimeo].

CASTELLS, M. A sociedade em rede - A era da informação: economia, sociedade e cultura. v.1. $11^{\circ}$ ed. São Paulo: Paz e Terra, 2008.

A galáxia da Internet: reflexões sobre a Internet, os negócios e a sociedade. Tradução de Maria Luiza Borges. Rio de Janeiro: Jorge Zahar, 2003.

CGEE - Centro de Gestão e Estudos Estratégicos. Doutores 2010: estudos da demografia da base técnico-científica brasileira - Brasília. Brasília, DF: CGEE, 2010.

COSTA, F. de A. Ciência, tecnologia e sociedade na Amazônia: questões para o desenvolvimento sustentável. Belém: NAEA, 2012.

FIALDINI JÚNIOR, A. Empreender com estratégia. In: ABC. Amazônia: desafio brasileiro do século XXI. São Paulo: Fundação Conrado Wessel, 2008. 
HITWISE. Ferramenta de pesquisa. Norte é a região que mais cresce em visitas na Internet. Disponivel em: < http://noticias.serasaexperian.com.br/ norte-\%C3\%A9-a-regi\%C3\%A3o-que-mais-cresce-em-visitas-na-internet-deacordo-com-pesquisa-do-hitwise/> . Acesso em:20 abr. 2011.

JORNAL BEIRA DO RIO. UFPA quer atrair novos doutores. Ano XXVII, n. 110, nov. 2011.

UFPA triplica cursos de pós-graduação. Ano XXVII, n. 104, maio 2012.

LÉVY, P. Cibercultura. São Paulo: Editora 34, 1999.

MALCHER, M. A.; RODRIGUES, R. O. Mirada sobre o cenário midiático amazônico. In: MALCHER, M. A.; MARQUES, J. A.; PAULA, L. R. de (Orgs.). História, Comunicação e Biodiversidade na Amazônia. Belém: Acquerello, 2012.

MARCHELLI, P. Formação de doutores no Brasil e no mundo: algumas comparações. Revista Brasileira de Pós-Graduação, Brasília, v.2, n.3, p.7-29, mar. 2005.

MATTOS, M. A.; VILLAÇA, R. C. Aportes para uma nova visada da metapesquisa em Comunicação. In: ENCONTRO DA COMPÓS, 20., 2011, Porto Alegre. Anais..., Porto Alegre: Compós, 2011.

MELO, L. C. P. de. Introdução. In: CGEE. Doutores 2010: estudos da demografia da base técnico-científica brasileira - Brasília. Brasília, DF: CGEE, 2010.

PAIVA, J. ; MACIEL, I. Redes cooperativas virtuais e formação continuada de professores: estudos para a graduação. In: REUNIÃO ANUAL DA ANPED, 23., 2000, Caxambu. Anais..., Caxambu: Anped, 2000.

ROCHA NETO, I. Prospectiva da Pós-Graduação no Brasil (2008-2022). Revista Brasileira de Pós-Graduação, Brasília, v.7, n.12, p.58-79, jul.2010.

RODRIGUES, R. de O. TV aberta no Marajó: usos e apropriações pelos moradores da comunidade São Pedro em Breves-Pará-Amazônia. 2012. 
Dissertação (Mestrado em Ciências da Comunicação)- Programa de PósGraduação em Comunicação, Cultura e Amazônia, Universidade Federal do Pará, Belém. 216 f.

STEINER, J. Conhecimento: gargalos para um Brasil no futuro. Revista Estudos Avançados (USP), v. 20, n. 56, jan./abr. 2006.

TOURINHO, E. Resultados da Avaliação da Pós-Graduação da UFPA. Jornal Beira do Rio, fev./mar. 2014.

UFPA - Universidade Federal do Pará. Relatório Anual - Ano base 2012. Belém, jan. 2013. 